\title{
On the Fidelity of "CORK" Borehole Hydrologic Observatory Pressure Records
}

by Earl Davis and Keir Becker

\section{Introduction}

Long-term formation pressure monitoring in Ocean Drilling Program (ODP) and Integrated Ocean Drilling Program (IODP) boreholes using evolving Circulation Obviation Retrofit Kit (CORK) hydrologic observatory technology has led to unanticipated applications as a result of the growing duration of recording intervals and the improvement of measurement fidelity. Current capabilities provide geologically meaningful observations over a broad range of time scales from static state to $1 \mathrm{~Hz}$, allowing investigations of many coupled hydrologic, geodynamic, and seismologic phenomena. In this review, we present observations that provide constraints on current limits to recording fidelity, and examples of how leakage can affect pressure observations.

\section{Background}

The capability to seal and monitor the hydrologic state of deep-ocean boreholes drilled by the ODP was developed in 1990 , and since that time, a broad range of experiments using this technology has been carried out to study the hydrogeology of ridge axes, older oceanic crust, and accretionary and non-accretionary subduction prisms. Original "CORK" installations (Fig. 1) employed a seal at the top of a standard solid steel casing string to isolate a single window of interest at depth for pressure monitoring and fluid sampling (Davis et al., 1992). Subsequent refinements (Fig. 1) have allowed pressure monitoring and fluid sampling at multiple formational levels outside and below the casing (Mikada et al., 2002; Jannasch et al., 2003; Becker and Davis, 2005). In both configurations, temperature measurements can be made inside and below the casing. Monitoring in installations completed to date has led to the determination of the static formation state and the driving forces and rates of fluid flow as originally planned, as well as to unexpected new insights regarding elastic and hydrologic formation properties, and secular and episodic strain in a variety of geologic settings and over a broad range of temporal and spatial scales (Davis and Becker, 2004; Becker and Davis, 2005; Kastner et al., 2007). In this article, we present data excerpts that illustrate the current level of recording fidelity, and we review problems experienced with some of the installations. Examples are drawn primarily from ocean crustal Site 1026 recently instrumented with new high resolution instrumentation, and sedimentary Sites 1173 and 808 at the Nankai subduction zone. While significant new insight has been gained through temperature monitoring and continuous fluid sampling, we limit this discussion to the measurement of pressure.

\section{Theoretical Limits to Resolution}

Limits to data quality are imposed by the characteristics of the measuring devices employed, and by the hydraulics of the CORK systems in context of the formations in which they are installed. All CORK systems deployed to date have been equipped with absolute pressure sensors (Paroscientific, Inc.) that utilize a quartz transducer loaded by the ocean- or formation-water pressure via a Bourdon tube. The pressuresensitive oscillation frequency of the transducer crystal is determined by comparing its output signal to a fixed reference frequency. Early electronics employed an integer cycle counter and provided a resolution of roughly $1 \mathrm{ppm}$ full-scale at $1 \mathrm{~Hz}$. In practice, memory and battery capacity limited sampling intervals to $1 \mathrm{hr}$ early in the development history, and this was later refined to 10 minutes. The intrinsic characteristics of the transducers allow much higher resolution to be achieved, and a recently developed fractional period counter (Bennest Enterprises, Ltd.) allows pressure to be

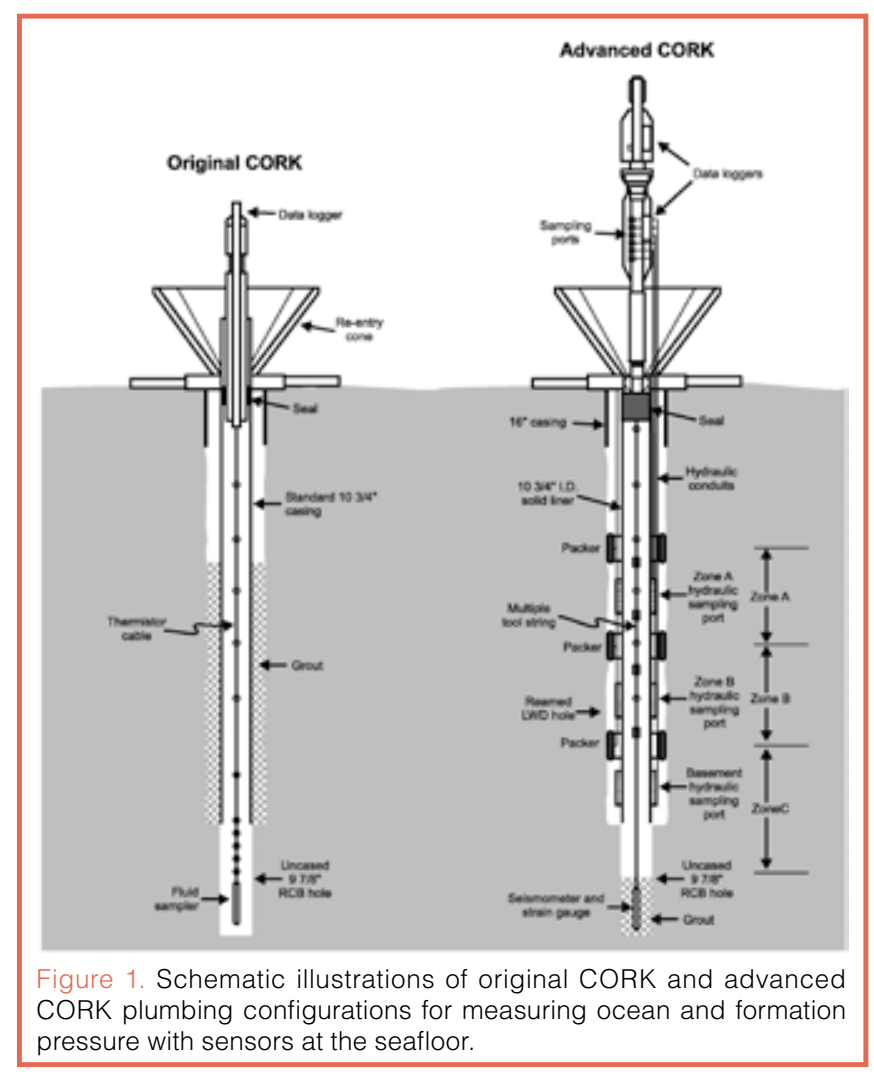


determined to a few tens of $\mathrm{ppb}(\sim 2 \mathrm{~Pa}$, or $0.2 \mathrm{~mm}$ of equivalent water head) at $1 \mathrm{~Hz}$. Autonomous deployments are still restricted to measurement frequencies lower than this, but instruments equipped with Bennest fractional-period counters soon to be connected to seafloor power and communications cables will allow full use of this "high-frequency" resolution. The highest autonomous sampling rate employed to date (15 s sample period at Site 1026) shows oceanographic signal levels approaching the theoretical limit (Fig. 2A).

At the low-frequency end of the spectrum, fidelity limits are imposed by sensor drift. Seafloor records from Sites 808 and 1173 (located $13 \mathrm{~km}$ from one another) show rates of drift that decrease from $\sim 5 \mathrm{kPa} \mathrm{yr}^{-1}$ in the first few months after deployment, to $\sim 0.1 \mathrm{kPa} \mathrm{yr}^{-1}$ over longer periods of time (Fig. 2B). Other sites show a similar behavior. Detection of natural secular change of formation pressures or water depths at rates less than this requires periodic calibration checks with a mobile sensor. Intermediate-period $(<1 \mathrm{yr})$ oceanographic signals (Fig. 2B) also impose limits on detecting tectonic signals, although local stable reference sites can help to overcome this problem. sedimentary sections are difficult to assess, but they are probably insignificant, since low sediment strength does not allow the formation to support its overburden, and collapse around the screens is likely to be complete and benign. A discussion of these factors and their possible influence on the frequency response of CORK systems is provided by Sawyer et al. Dependence of the system response on the primary factors of sediment compressibility, permeability, and CORK-system compliance, can be understood using a formulation of Bredehoeft and Papadopulos (1980) for well-bore response to a step-wise change in formation pressure. Parameters that cover the range of CORK installations are provided in Table 1, and the results are summarized in Fig. 3. In Fig. 3A, dimensionless time incorporates scaling for formation permeability and compressibility; when converted to real time (Fig. 3B), the orders-of-magnitude difference in sediment and basalt permeabilities result in much faster response times for a CORK in basalt compared to a CORK in sediment, despite the fact that their type curves are similar (Fig. 3A). The differences among the type curves also involves a scaling for system volume, leading to a much faster actual response time for an ACORK vs. a CORK in sediment (Fig. 3B).
Hydraulic-system limits on fidelity originate primarily from the inability of the formation to deliver or receive fluid rapidly enough to accommodate compliance in the CORK plumbing as formation pressure changes. The most influential formation and CORK system properties are hydraulic storage compressibility and permeability, and plumbing volume and fluid compressibility, respectively. Original CORKs utilized the full volume of the cased holes to transmit formation pressure to the sensors at the seafloor (Fig. 1). A significant reduction in the system fluid volume and associated compliance was gained by later CORKs (collectively referred to herein as "advanced CORKs", or ACORKs) which used small-diameter hydraulic lines running from the sensors to relatively small-volume permeable formation screens (Fig. 1; Table 1). Compliance of the all-steel plumbing components is negligible relative to the water they contain. Entrained gas can strongly affect the plumbing compressibility, but purging during (and often after) deployment has been done to reduce or eliminate this factor. Hydraulic resistance and compliance in the annulus outside the casing screens in

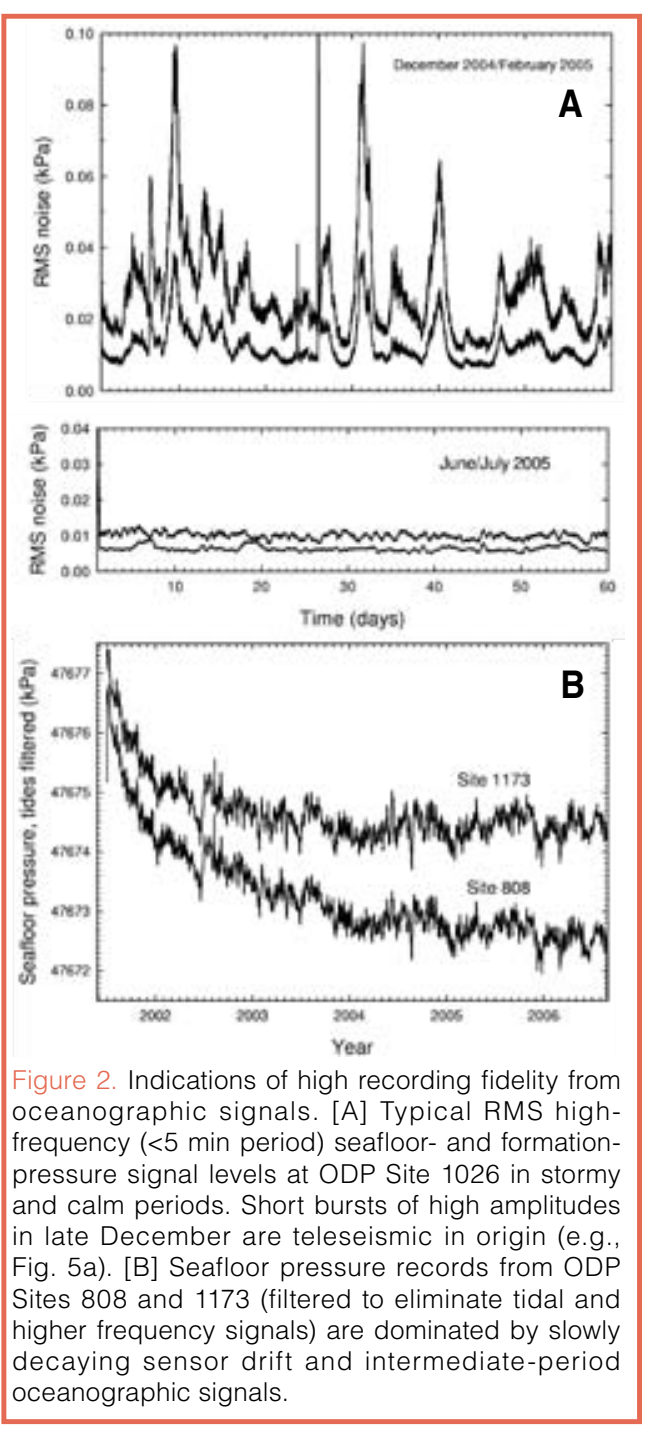

\section{Observational Indications of High Data Quality}

The best examples of current intrinsic recording capability at high frequencies are provided by a new-generation (Bennest fractional period counter) instrument installed on the Juan de Fuca Ridge flank in Hole 1026B in 2004 during IODP Expedition 301. This modified (Fisher et al., 2005) CORK samples highly permeable oceanic crust, and CORK system effects are probably small (Fig. 3B). Time-series data suggest uniform elastic formation response to oceanographic loading over a broad range of frequencies (Fig. 4). A slight flattening of the seafloor- and formation-pressure power spectra at high frequencies may indicate approach to the sensor noise floor, although this is not surprising, given that the high-frequency signal levels during oceanographically quiet times are only $\sim 10 \mathrm{~Pa}$, i.e., close to the $2 \mathrm{~Pa}$ measurement resolution (Fig. 2A). Other indications of recording fidelity at high frequency have been provided by signals of geologic origin. An example of pressure signals from the Sumatra earthquake of 2004 includes seismic body waves that are smaller in amplitude in the for- 


\begin{tabular}{|c|c|c|c|}
\hline Property & CORK in basalt & CORK in sediment & ACORK in sediment \\
\hline Fluid compressibility & $0.4 \times 10^{-9} \mathrm{~Pa}^{-1}$ & $0.4 \times 10^{-9} \mathrm{~Pa}^{-1}$ & $0.4 \times 10^{-9} \mathrm{~Pa}^{-1}$ \\
\hline Formation compressibility & $10^{-9} \mathrm{~Pa}^{-1}$ & $10^{-8} \mathrm{~Pa}^{-1}$ & $10^{-8} \mathrm{~Pa}^{-1}$ \\
\hline Permeability & $10^{-10} \mathrm{~m}^{2}$ & $10^{-18} \mathrm{~m}^{2}$ & $10^{-18} \mathrm{~m}^{2}$ \\
\hline Fluid viscosity & $0.4 \times 10^{-3} \mathrm{~Pa} \mathrm{~s}$ & $0.4 \times 10^{-3} \mathrm{~Pa} \mathrm{~S}$ & $0.4 \times 10^{-3} \mathrm{~Pa} \mathrm{~s}$ \\
\hline System volume & $30 \mathrm{~m}^{3}$ & $30 \mathrm{~m}^{3}$ & $0.064 \mathrm{~m}^{3}$ \\
\hline Window length & $50 \mathrm{~m}$ & $50 \mathrm{~m}$ & $7.6 \mathrm{~m}$ \\
\hline Window radius & $0.15 \mathrm{~m}$ & $0.15 \mathrm{~m}$ & $0.15 \mathrm{~m}$ \\
\hline Porosity & 0.1 & 0.4 & 0.4 \\
\hline Storage compressibility & $1.04 \times 10^{-9} \mathrm{~Pa}^{-1}$ & $1.02 \times 10^{-8} \mathrm{~Pa}^{-1}$ & $1.02 \times 10^{-8} \mathrm{~Pa}^{-1}$ \\
\hline
\end{tabular}

mation than in the water column, and surface waves that are larger in the formation (Fig. 5A). The formation/seafloor amplitude ratio for the $\mathrm{P}$ waves is consistent with that for ocean waves and tides ( 0.3). The amplitude ratio for the surface waves $(\sim 2.5)$ is much larger.

As yet, no high resolution instruments have been installed in any sedimentary formations, and the limits of the oldgeneration instruments do not allow oceanographic signals to be used to assess the point at which CORK or ACORK hydraulic systems filter high-frequency hydrologic signals. Signals of geologic origin do provide relevant information. Observation of a static strain step recorded at Site 1173 (Fig. 5b) provides confidence that this low-system-volume ACORK provides reasonable high-frequency fidelity, despite the low formation permeability. Response to what is probably a step-wise change in formation pressure (reflecting coseis-
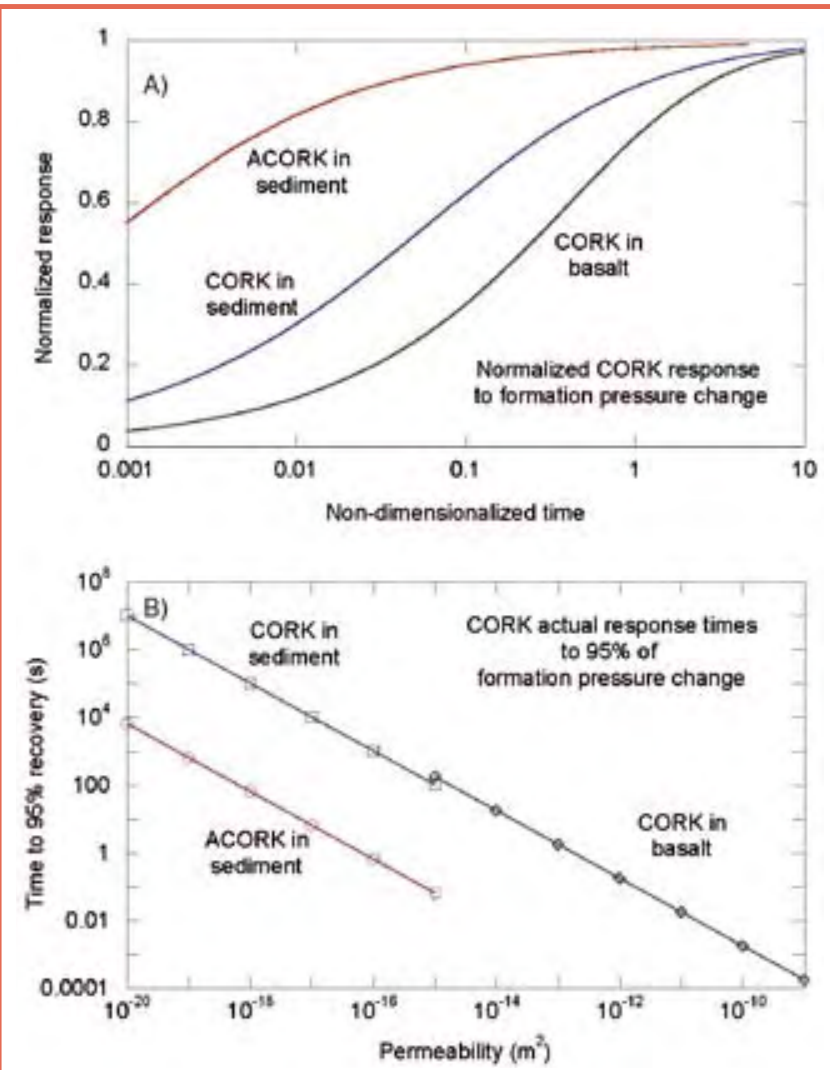

Figure 3. Simulated CORK and ACORK system response to a step change in formation pressure. [A] Characteristic Bredehoeft and Papadopulos (1980) type-curves for three example configurations (see parameter values in Table 1). [B] Dependence on formation permeability of actual CORK response times to $95 \%$ of the formation pressure change i.e., when curves reach 0.95 in $[A]$ mic volumetric contraction; Davis et al., 2007) is rapid ( $\leq 10$ minutes, as predicted by Fig. 3 ). Seismic waves are also seen in this record, although the 10-min sampling interval causes the recorded signal to be highly aliased. In the future, higher resolution and higher sampling frequency will allow the full system fidelity to be properly examined.

\section{Pitfalls}

While CORK pressure monitoring to date has been generally very successful and the fidelity generally high, hydraulic leakage caused by physically damaged, hydrothermally deteriorated, or missing seals has impaired the fidelity of monitoring at several sites. Where leaks occur, measured formation pressure can be affected directly by pressure loss through the leaks, although most problems have arisen indirectly through effects of thermal buoyancy and thermal expansion associated with steady or transient flow up or down the leaking borehole along the geothermal gradient. A record from Site 1025 on the Juan de Fuca Ridge flank (Fig. 6a) illustrates a case where thermal buoyancy contributes most to a leakage-induced pressure perturbation. When a fluid sampling valve was opened, the record became noisy, the tidal signal was distorted, and the static pressure rose above the natural formation pressure as a consequence of the buoyancy of the warm discharge through the CORK casing from the slightly super-hydrostatic formation. Such perturbations arise whenever pressures are measured in high-permeability formations in the presence of leaks.

A different effect has been witnessed in two ACORKs that penetrate low-permeability sediments, namely Site 1173, where fluid sampling valves connected to some of the umbilical tubes were manipulated during monitoring, and Site 808 , where pressures in multiple screens were affected by flow inside the casing from a permeable fault zone at depth. In this latter instance, a plug was to have been installed inside the main casing (Fig. 1), but drilling difficulties precluded this operation. Most of the screens appear to have been hydrologically well isolated and coupled to the formation at this site, but there was no check against flow up the inside of the casing from its bottom end. Several initially puzzling observations can be explained by thermal expansion and contraction of fluid in the lines and in low-permeability parts of the formation outside the screens caused by variable heating and cooling by the unwanted vertical flow: 
Tidal loading response: The first of these observations is the occurrence of unusual formation tidal signals. Normally, formation response should reflect elastic deformation of the formation matrix under the influence of seafloor loading, with little or no phase between the loading and response. Given the compressibility of the sediments at Nankai (Bourlange et al., 2005), the amplitude of the formation pressure signal should be reduced to roughly $90 \%$ of that at the seafloor (Wang and Davis, 1996). In several instances, very unusual response is seen relative to these expectations. During part of the early history of recording at the deepest screen at Site 1173 , when valves to higher screens were unintentionally left open, the amplitude of the formation tidal signal at the deepest screen actually exceeded that at the seafloor, and the sign was reversed (Fig. 6B). At Site 808, tidal signals at most of the screens are characterized by large phases and unreasonable levels of attenuation during most of the recording period (Fig. 6C). This behavior has been described in detail by Sawyer et al. who have attributed it to purely hydrologic interaction between the ACORK measurement system and the formation. Inexplicably large compliance in the ACORK plumbing and a large resistive "skin" effect at the screens are required to account for most of the behavior observed, however, and the signal amplification and sign reversal seen in Fig. $6 \mathrm{~b}$ cannot be accounted for in this way at all.

High-frequency noise: Another noteworthy characteristic of the records from Site 808 is the persistence of high frequency pressure variations riding on the tidal signal that are highly correlated among multiple levels (Fig. 6C). The magnitude of this noise is consistently greatest for those screens that display the most anomalous tidal response. Whatever the source of this noise, it must act consistently over the full section of the hole to produce the coherence observed.

"Cross-talk": A third observation that provides key evidence for thermal expansion effects is of apparent cross-talk between certain screens at Site 1173. This is particularly well illustrated by the example at the end of the record shown in Fig. 6D, when a small-diameter geochemical sampling line was opened for testing. This line is terminated in screen 4 , and as expected, pressure measured in the parallel monitoring line connected to that screen fell slightly when the sampling valve was opened. At the same time, pressures in the lines terminating at screens 1 and 3 rose by an amount roughly ten times greater than the drop registered at screen 4. A similar but seemingly opposite interaction was witnessed when the monitoring line valves were closed in 2002 . Pressures at screen 1 dropped at the time of valve closure by $80 \mathrm{kPa}$ to a seemingly inexplicable sub-hydrostatic level at the time the valves to other lines in the umbilical were closed.

Strain transients: Perhaps the most enigmatic observation is of impulsive pressure transients observed at Site 808
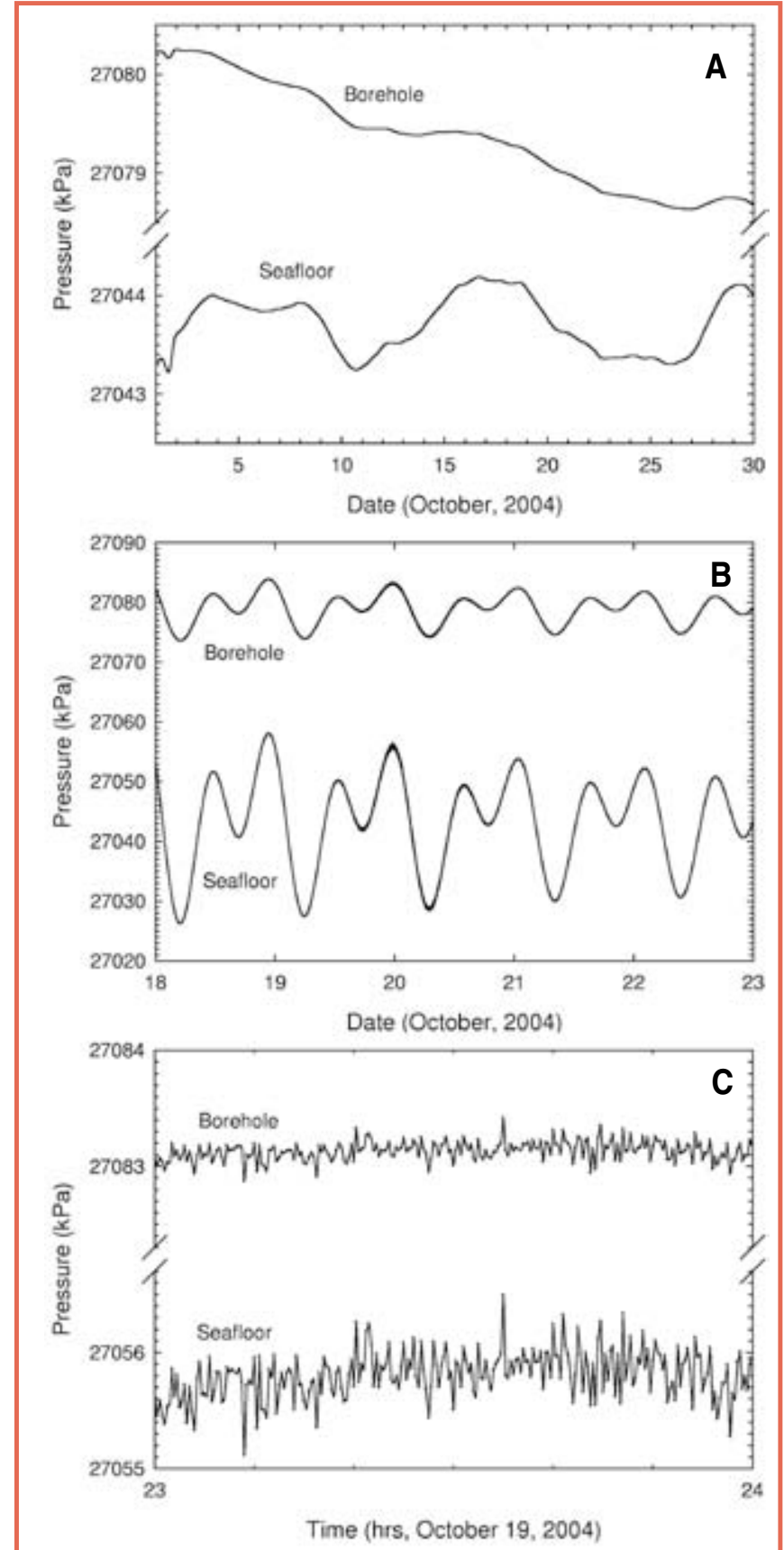

Figure 4. Typical formation-pressure response to [A] long-period, [B] tidal, and $[\mathrm{C}]$ infragravity sea-surface wave loading observed with a high resolution monitoring instrument at ocean crustal Site 1026

at the times of two seismic events (Fig. $6 \mathrm{E}$ and $6 \mathrm{~F}$ ). The transients contrast with simultaneous step-wise changes in pressure observed at Site 1173 (e.g., Fig. 5B); the earlier transient pulse was initially interpreted to be a signature of near-field transient strain associated with slip on the decollement immediately beneath the observation screens (Davis et al., 2006). This interpretation is almost certainly wrong.

All of these unusual observations can be accounted for by a single mechanism - thermal expansion and contraction of water in the umbilical tubing and screens and in the formation surrounding the screens, caused by variable vertical fluid flow inside the large diameter casing (Site 808) and in the opened sampling/monitoring lines of the hydraulic umbilical (Site 1173). Given the large contrast between the 

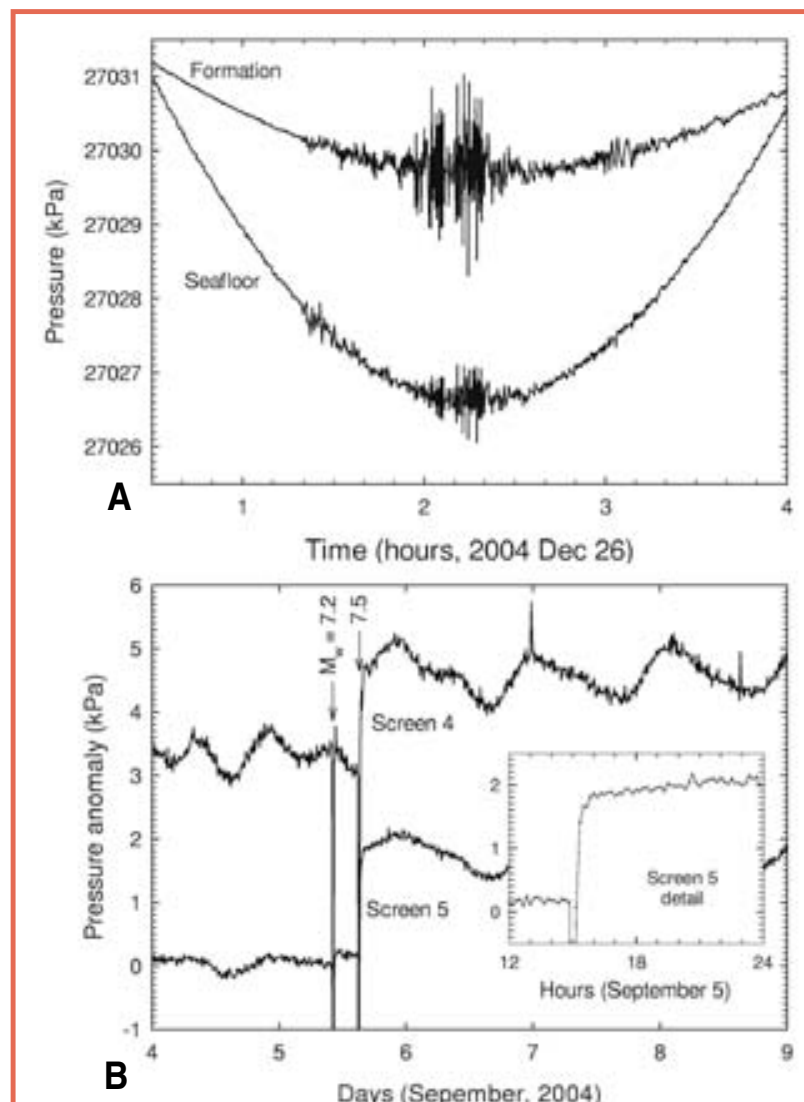

Figure 5. Indications of high recording fidelity from geologic signals. [A] Seismic waves from the December 2004 Sumatra Mw=9.0 earthquake. [B] Pressure steps observed in the sediments of the Philippine Sea plate off the Nankai subduction zone caused by regional volumetric strain associated with seismogenic rupture of the oceanic plate $220 \mathrm{~km}$ to the northwest off the Kii peninsula, Japan (Davis et al., 2007).

thermal expansivity and volumetric compressibility of water $\left(\sim 0.4 \times 10^{-3} \mathrm{~K}^{-1}\right.$ and $\sim 0.4 \times 10^{-9} \mathrm{~Pa}^{-1}$, respectively), temperature sensitivity is inevitable wherever screens are well coupled to low-permeability sediments (like those of the lower Shikoku basin facies). The contrast yields a sensitivity of pressure to temperature of roughly $1 \mathrm{kPa} \mathrm{mK}^{-1}$. Pressures may be produced with this efficiency if the temperature variation is coherent along the full distance from the screens to the sea-floor (an inevitable outcome of flow up or down the geothermal gradient), and if the sediment permeability at a given screen is sufficiently low to prohibit drainage at the rate of volumetric expansion. Whether this condition is met can be evaluated by considering the contrast between the thermal diffusivity $\left(\sim 10^{-7} \mathrm{~m}^{2} \mathrm{~s}^{-1}\right)$ and the hydraulic diffusivity. Thermal diffusion can indeed outpace hydrologic diffusion in sediments like those of the Lower Shikoku Basin facies, which have a hydraulic diffusivity of $\sim 2.5 \times 10^{-9} \mathrm{~m}^{2} \mathrm{~s}^{-1}$ (Bourlange et al., 2005; Gamage and Screaton, 2005; Table 1). Some inefficiency will result from thermal expansion of the tubing itself, and from the attenuation and time lag of thermal diffusion between the source of the thermal perturbation and the umbilical tube, screen, or sediment where the consequences of expansion are observed. The first factor is insignificant, given the large contrast in expansivity between water and steel. The importance of the second will vary with the frequency of the signal and with the time constant for the

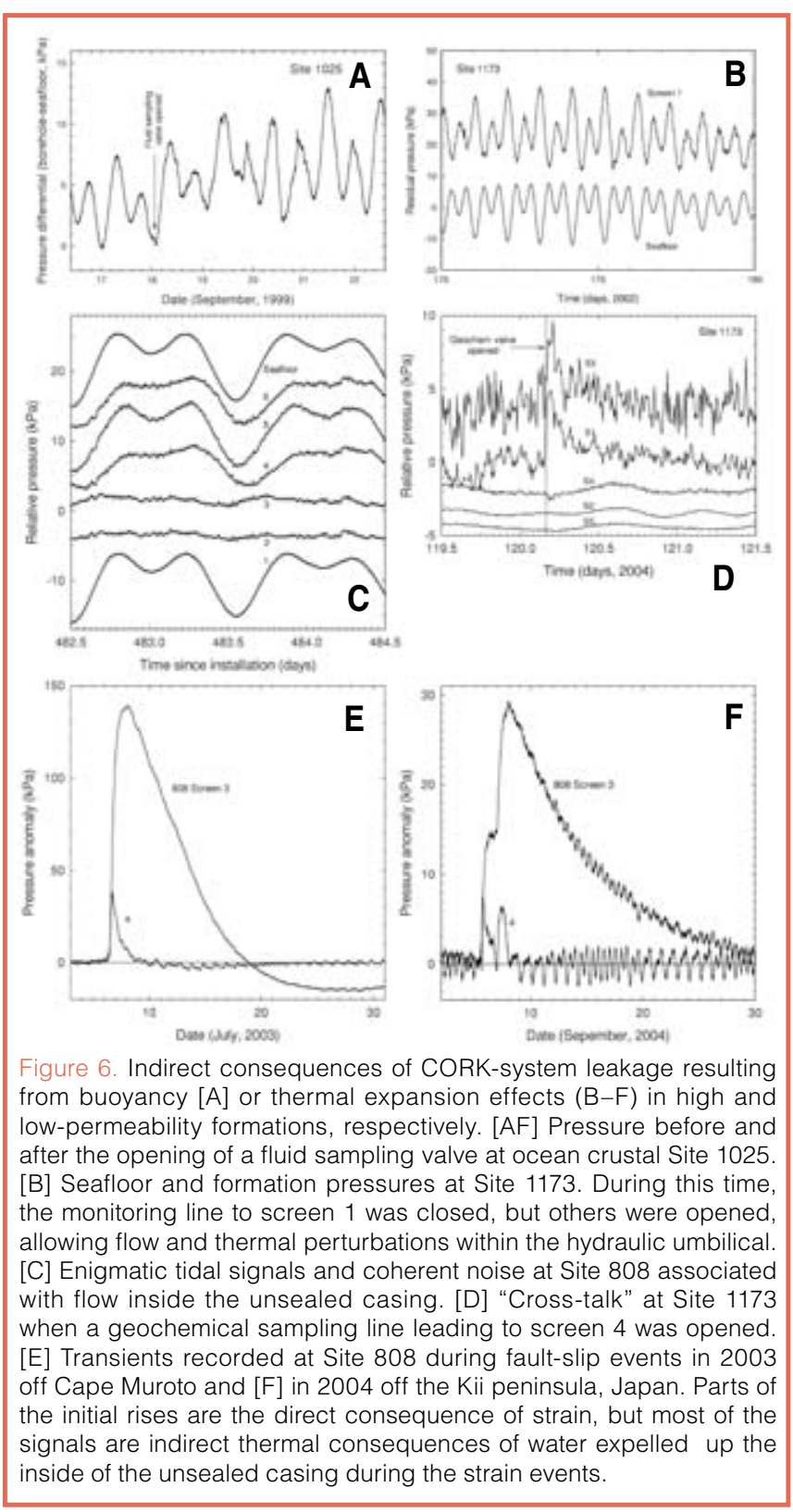

thermal path (e.g., $\sim 1 \mathrm{hr}$ for conduction between the inside of the $10.75^{\prime \prime}$ casing and the formation, screens, or umbilical outside, and $\sim 1 \mathrm{~min}$ for conduction between tubes within the umbilical).

\section{Summary and Recommendations}

The fidelity of CORK formation pressure records appears to be high over a broad frequency range. After pressure transducers equilibrate to ambient pressure, long-term drift is typically about $0.1 \mathrm{kPa} \mathrm{yr}^{-1}$. Response at high measurement frequencies (a few $\mathrm{Pa}$ at $1 \mathrm{~Hz}$ ) is good in high permeability formations, but CORK-system compliance may influence the fidelity of observations in very-low-permeability lithologies, even with the low-system-volume advantage offered by ACORK configurations.

Several lessons have been learned through inevitable installation errors, and these should be highlighted. 
1) Consequences of leakage can degrade fidelity over a broad frequency range and they can be difficult to discriminate from real signals. A good example of this is provided by impulse transients witnessed at two strain events at the Nankai accretionary prism (Figs. 6E, 6F) which are now believed to be the result of umbilical- and formation-fluid thermal expansion caused by strain-induced flow inside the unsealed casing.

2) Leakage can be efficiently assessed by the measurement of temperature. At Nankai, installation of temperature sensors was planned, but was precluded by the same operational problem that prevented the installation of an internal casing seal. Great care must be used in the future to prevent and detect leaks.

3) Entrained CORK fluid volume should be minimized and screen area maximized to enhance the inherent system fidelity by reducing the time constant associated with the coupling between the measurement system and the formation. This will have the added benefit of reducing the geochemically perturbing effects of "foreign" water.

\section{Acknowledgments}

We thank the ODP and the captains and crew of the JOIDES Resolution for ongoing support for long-term borehole monitoring experiments. Appreciation is also given to T. Pettigrew, R. Meldrum, and R. Macdonald for engineering assistance. We are grateful to the pilots and crews of the submersibles Alvin, Nautile, and Shinkai 6500 and remotelyoperated vehicles ROPOS, Jason, Kaiko $12 k$, and Kaiko $7 k$ for instrument installations and data downloads. We would also extend our gratitude to the captains and crews of the respective support vessels for their multi-faceted support during site visits. Financial support has been provided by the U.S. National Science Foundation (NSF), the Geological Survey of Canada (GSC), and the Japanese Center for Marine Science and Technology (JAMSTEC).

\section{References}

Bredehoeft, J.D., and Papadopulos, S.S., 1980. A method for determining the hydraulic properties of tight formations. Water Resources Res., 16:223-238.

Becker, K., and Davis, E.E., 2005. A review of CORK designs and operations during the Ocean Drilling Program. In Fisher, A.T., Urabe, T., Klaus, A., and the Exp. 301 scientists (Eds.), Proc. IODP, Init. Repts. 301. College Station, Texas (IODP), 1-28 (DVD).

Bourlange, S., Jouniaux, L., and Henry, P., 2005. Data report: Permeability, compressibility, and friction coefficient measurements under confining pressure and strain, Leg 190, Nankai Trough. In Mikada, H., Moore, G.F., Taira, A., Becker, K., Moore, J.C., and Klaus, A. (Eds.), Proc. ODP Sci. Results 190/196, College Station, Texas (IODP), 1-16 (DVD).

Davis, E.E., and Becker, K., 2004. Observations of temperature and pressure: Constraints on ocean crustal hydrologic state, properties, and flow. In Davis, E.E., and Elderfield, H. (Eds.), Hydrogeology of the Oceanic Lithosphere, Australia (Cambridge University Press), 225-271.
Davis, E.E., Becker, K., Pettigrew, T., Carson, B., and MacDonald, R., 1992. CORK: A hydrologic seal and downhole observatory for deep ocean boreholes. In Davis, E.E., Mottl, M.J., and Fisher, A.T. (Eds.), Proc.ODP Init. Rep. 139, College Station, Texas (ODP), 43-53.

Davis, E.E., Becker, K., Wang, K., Obara, K., Ito, Y., and Kinoshita, M., 2006. A discrete episode of seismic and aseismic deformation of the Nankai subduction zone accretionary prism and incoming Philippine Sea plate. Earth Planet. Sci. Lett., 242:73-84, doi:10.1016/j.epsl.2005.11.054.

Davis, E.E., Wang, K., Becker, K., and Kinoshita, M., 2007. Co- and post-seismic crustal contraction and fault-zone dilatation, Nankai subduction zone. Nature, in press.

Fisher, A.T., Wheat, G.C., Becker, K., Davis, E., Hannasch, H., Schroeder, D., Dixon, R., Pettigrew, T., Meldrum, R., Macdonald, R., Nielsen, M., Fisk, M., Cowen, J., Bach, W., and Edwards, K., 2005. Scientific and technical design and deployment of long-term subseafloor obseratories for hydrogeologic and related experiments, IODP Expedition 301, eastern flank of Juan de Fuca Ridge. In Fisher, A.T., Urabe, T., Klaus, A., and the Expedition 301 Scientists, Proc. IODP, 301: College Station, Texas (IODP-MI, Inc.). doi:10.2204/ iodp.proc.301.103.2005.

Gamage, K., and Screaton, E., 2005. Data report: Permeabilities of Nankai accretionary prism sediments. In Midaka, H., Moore, G.F., Taira, A., Becker, K., Moore, J.C., and Klaus, A. (Eds.), Proc. ODP Sci. Res. 190/196, College Station, Texas (ODP), 1-22 (DVD).

Jannasch, H.W., Davis, E.E., Kastner, M., Morris, J.D., Pettigrew, T.L., Plant, J.N., Solomon, E.A., Villinger, H.W., and Wheat, C.G., 2003. CORK II: Long-term monitoring of fluid chemistry, fluxes, and hydrology in instrumented boreholes at the Costa Rica subduction zone. In J.D. Morris, H.W. Villinger, A. Klaus, et al. (Eds.), Proc. ODP, Init. Rep. 205, College Station, Texas (ODP).

Kastner, M., Becker, K., Davis, E.E., Fisher, A.T., Jannasch, J.W., Solomon, E.A., and Wheat, C.G., 2007. New insights into the hydrogeology of the oceanic crust through long-term monitoring. Oceanogr., 19:46-57.

Mikada, H., Becker, K., Moore, J.C., Klaus, A., and the Shipboard Scientific Party, 2002. Deformation and fluid flow processes in the Nankai Trough accretionary prism: Logging while drilling and advance CORKs. Proc. ODP, Init. Rep. 196, College Station, Texas (ODP).

Sawyer, A.H., Flemings, P.B., Elsworth, D.E., and Kinoshita, M., in press, Response of Submarine Hydrologic Monitoring Instruments to Formation Pressure Changes: Theory and Application to Nankai ACORKs, Journal of Geophysical research.

Wang, K., and Davis, E.E., 1996. Theory for the propagation of tidally induced pore pressure variations in layered subseafloor formations. J. Geophys. Res., 101:11483-11495, doi:10.1029/96JB00641.

\section{Authors}

Earl Davis, PGC, Geological Survey of Canada, 9860 West Saanich Road, North Saanich, Sidney, British Columbia V8L 4B2, Canada, e-mail: edavis@nrcan.gc.ca.

Keir Becker, RSMAS/MGG, University of Miami, 4600 Rickenbacker Causeway, Miami, Fla. 33149-1098, U.S.A. 